\title{
CIDADANIZAÇÃO E ETNOGÊNESES NO BRASIL: APONTAMENTOS A UMA REFLEXÃO SOBRE AS EMERGÊNCIAS POLÍTICAS E SOCIAIS DOS POVOS INDÍGENAS NA SEGUNDA METADE DO SÉCULO XX
}

Citizenization and Ethnogeneses in Brazil: notes on a reflection about the Political and Social Emergencies of Indigenous Peoples in the Second Half of the Twentieth Century

Ciudadanización y etnogénesis en Brasil: apuntes a una reflexión sobre las emergencias políticas y sociales de los pueblos indígenas en la segunda mitad del siglo XX

\section{FERNANDO ROQUE FERNANDES}




\section{RESUMO}

Historicamente os povos indígenas têm se articulado na luta por seus direitos frente à comunidade. Muitos grupos, ao usarem estratégias específicas, desenvolveram processos de emergências políticas na luta pelo reconhecimento de suas diferenças. A partir da Constituição de 1988 e devido a importantes fenômenos sociais, muitos grupos passaram a ter seus direitos humanos reconhecidos juridicamente. Acreditamos que as associações e organizações indígenas e pró-indígenas que emergiram a partir da segunda metade do século XX articularam estratégias particulares que resultaram no reconhecimento das especificidades dos povos indígenas frente ao Estado brasileiro. A nosso ver, fenômenos de etnogênese e etnicidade constituem a base do protagonismo indígena na história do Brasil.

PALAVRAS-CHAVE: Protagonismo indígena; Movimentos indígenas; Cidadanização; Século XX.

\section{ABSTRACT}

Historically, indigenous peoples have been uniting in the fight for rights in relation to the surrounding community. Many groups, using specific strategies, have developed processes of political emergencies in the struggle for the recognition of their differences. Ever since the Constitution of 1988 and due to important social phenomena many groups began to have their human rights legally recognized. We believe that the indigenous and pro-indigenous associations and organizations that emerged from the second half of the twentieth century devised particular strategies that resulted in the recognition of the specificities of the indigenous peoples vis-à-vis the Brazilian State. In our view, ethnogenesis and ethnicity phenomena in Brazilian history.

KEYWORDS: Indigenous prominence; Indigenous movements; Citizenization; Twentieth century.

\section{RESUMEN}

Históricamente, los pueblos indígenas se han articulado en la lucha por derechos frente a la comunidad circundante. Muchos grupos, al utilizar estrategias específicas, desarrollaron procesos de emergencias políticas en la lucha por el reconocimiento de sus diferencias. A partir de la Constitución de 1988 y debido a importantes fenómenos sociales esos pueblos pasaron a tener sus derechos humanos reconocidos jurídicamente. Creemos que las asociaciones y organizaciones indígenas y pro-indígenas que emergieron a partir de la segunda mitad del siglo XX, articularon estrategias particulares que resultaron en el reconocimiento de las especificidades de los pueblos indígenas frente al Estado brasileño. A nuestro ver, fenómenos de etnogénesis y etnicidad constituyen la base del protagonismo indígena en la historia de Brasil.

PalabRAS ClAVE: Protagonismo Indígena; Movimientos Indígenas; Ciudadanización; Siglo XX. 


\section{A CONSTITUCIONALIZAÇÃO DOS DIREITOS INDÍGENAS}

quele foi um dia formidável para a história do País! Era o ano de 1988, especifica-
mente, dia 22 de setembro. A sociedade brasileira já estava, havia tempos, antenada nas discussões relacionadas à criação de uma Constituição que normatizasse os direitos e fundamentos daquele "novo", mas incipiente regime democrático.

Pelos bares, restaurantes, aeroportos, praças, salões de beleza, nas esquinas, campos, ou como se diz em certas localidades: Pelos rincões do Brasil! Pelas aldeias e comunidades ribeirinhas, pelos sertões etc. Nos diferentes espaços, pessoas das mais distintas situações econômicas, políticas e sociais debatiam, conectadas por uma discussão indispensável aos rumos políticos que iriam impactar na forma como os discursos sobre a ideia de Estado Nacional' se conformariam nos tempos vindouros.

Emblemático dia para os diferentes atores sociais, inesquecível para diferentes tipos sociais. Se a Carta Magna seria ou não respeitada, conforme os ditames nela prescritos, isso tem a ver com os processos históricos, fundamentados em conjunturas que não seriam possíveis de mensurar naquele contexto. A Constituição apresentava o resultado de calorosos debates ocorridos até aquele momento.

O texto constitucional, apesar das limitações conjunturais, refletia, em certo sentido, os anseios de diferentes setores da sociedade civil, reconhecendo, pelo menos em caráter jurídico, alguns dos direitos de diferentes grupos sociais e étnicos residentes no denominado Território Nacional - ou, como se tem destacado em trabalhos recentes que tratam do multiculturalismo na América Latina, nos territórios do Estado Plurinacional (Lacerda, 2014: 8). ${ }^{2}$

De acordo com a afirmação do líder do Partido da Frente Liberal (PFL, 1985-2007 - partido de centro-direita), José Lourenço, "A nova Constituição [era], antes de tudo, um retrato fiel do esforço e do embate das múltiplas forças e interesses [ali] representados" (Jornal do Brasil, 23 set. 1988: 2). Apesar da emblemática aprovação do texto constitucional, nem todos os presentes foram a favor da Carta. Foram 474 votos a favor, 15 contra e 6 abstenções. Acrescentam-se a esses números os 64 constituintes que não estiveram presentes na votação, dos quais 15 estariam na Bulgária, participando da Reunião Plenária da Interparlamentar Mundial. O Partido dos Trabalhadores (PT, fundado em 1980 - partido de esquerda), liderado pelo então deputado federal Luiz Inácio Lula da Silva (SP), demonstrava insatisfação com os resultados alcançados pela Constituinte. Em discurso proferido naquele dia, Lula destacava:

[...] Importante na política é que tenhamos espaço de liberdade para ser contra ou a favor. E o Partido dos Trabalhadores, por entender que a democracia é algo importante - ela foi conquis- 
tada na rua, ela foi conquistada nas lutas travadas pela sociedade brasileira -, vem aqui dizer que vai votar contra esse texto, exatamente porque entende que, mesmo havendo avanços na Constituinte, a essência do poder, a essência da propriedade privada, a essência do poder dos militares continua intacta nesta Constituinte. Ainda não foi desta vez que a classe trabalhadora pôde ter uma Constituição efetivamente voltada para os seus interesses. Ainda não foi desta vez que a sociedade brasileira, a maioria dos marginalizados, vai ter uma Constituição em seu benefício [...] (DANC, 23 set. 1988: 14.313-14.314).

O Partido Democrático Social (PDS/1980-1992 - partido de centro-direita), transfiguração do conhecido Aliança Renovadora Nacional (ARENA/1965-1980 - sustentáculo do regime civil militar), por meio de seu presidente, senador Jarbas Passarinho, seguia os interesses da maioria dos líderes de bancada, contrariando as "minorias" e chegando a enfatizar que "ninguém poderá arrogar-se o direito de insurgir-se contra ela" (Jornal do Brasil, 23 set. 1988: 2).

Foram 20 meses de trabalho, 912 votações em plenária e mais de 65 mil emendas apreciadas. Presidente da Constituinte e do Partido do Movimento Democrático Brasileiro (PMDB/Fundado em 1980 - principal opositor do regime civil militar), Ulysses Guimarães arrogava: "Chegamos, nós chegamos. Graças a Deus, à sociedade, aos constituintes e ao povo brasileiro, chegamos!" A nova Carta com 245 artigos no corpo permanente e 70 nas disposições transitórias entraria em vigor no dia 5 de outubro daquele corrente ano. 0 então senador e presidente do Partido da Social Democracia Brasileira (PSDB/Criado em 1988 - partido com ideologias centro-esquerdistas), Fernando Henrique Cardoso (FHC), pronunciava na tribuna:

[...] Pela primeira vez na história do Brasil e talvez do mundo, se faz uma constituição com a colaboração direta da cidadania. Recebemos milhões de assinaturas em emendas populares e o povo sentiu de perto o que é consciência dos nossos direitos; entendeu rapidamente que, sem liberdade, não há avanço social. 0 Congresso foi durante a Constituinte um grande ponto de encontro de empresários, sindicalistas, representantes de igrejas, de nações indígenas, professores e estudantes. Foi uma amostra de todo o Brasil que, tocado pela consciência de que era hora de mudar, veio e pressionou. Se mais não fizemos, foi porque mais não pudemos. Mas esta Constituinte despertará o país para que se organize, para que possamos avançar mais [...] (Jornal do Brasil, 23 set. 1988: 4) grifo do autor.

Observe que FHC, ao reconhecer a participação de diferentes agentes sociais, inclusive indígenas, na construção da Carta de 1988, permite-nos refletir sobre a conjuntura social do País naquele período. Os jornais da época publicaram centenas de matérias relacionadas à precariedade em que se encontrava a população brasileira. Problemas na área da saúde, 
saneamento básico e educação estiveram sempre entre os grandes problemas a serem resolvidos. Os diversos conflitos pela posse e usufruto da terra - historicamente parte da realidade do País - estavam longe de uma solução pacífica. ${ }^{3}$

A questão é que a crescente circulação de ideias liberais de caráter internacional e o desenvolvimento de partidos políticos, organizações e associações de caráter popular em âmbito local, regional e nacional, bem como as diferentes notícias sobre a possibilidade de abertura política que sangravam as rádios e jornais na década de 1980, parecem ter criado uma espécie de conscientização que se materializava por meio das mobilizações sociais, voltadas ao processo de cidadanização das camadas menos favorecidas na sociedade brasileira, nas quais se incluíam, também, povos indígenas e comunidades quilombolas. ${ }^{4}$ Decorreram também grandes conflitos por conta da implementação de políticas desenvolvimentistas de caráter liberal-capitalista.

Tânia Guimarães Ribeiro (2010), ao analisar o conceito de desenvolvimento participativo nas ações do Estado e suas propostas para a Amazônia, observou que conceitos como desenvolvimento socioeconômico e desenvolvimento participativo concorreram para a criação de políticas públicas voltadas ao atendimento, ainda que quase imperceptível, das necessidades das camadas menos favorecidas na região Norte do País. Ribeiro (2010) constatou que determinadas políticas sociais só puderam se desenvolver com o amparo da sociedade civil. Apesar de a autora não destacar o posicionamento dos povos indígenas frente às políticas desenvolvimentistas para a Amazônia, é possível constatar que desses projetos resultaram sempre grandes conflitos com estas comunidades, principalmente no que diz respeito às questões ligadas às terras indígenas e aos projetos integracionistas, pensados para as pessoas e a região.

Para além dos movimentos sociais de caráter urbano, "minorias étnicas", como os povos indígenas, declaravam suas insatisfações pelo não reconhecimento de seus direitos políticos e sociais relacionados às questões de terra, saúde, saneamento básico e educação. Poliene Soares dos Santos Bicalho (2010), ao analisar os movimentos indígenas ocorridos no Brasil, entre os anos de 1970 e 2009, observou que a luta pelo reconhecimento e a garantia dos direitos indígenas tornou-se mais evidente durante os trabalhos da Assembleia Nacional Constituinte, em 1987. A nosso ver, a conformação da nacionalidade brasileira resulta das intensas agitações políticas e sociais características das relações de contato. Nesse sentido, a Constituinte de 1988 parece resultar de ambos os processos, iniciados no calor das incipientes "descobertas".

A representação indígena, conforme apontado no discurso de FHC (1988) e na tese de Bicalho (2010) se fez presente no processo de formulação do texto constitucional. Uma das figuras mais emblemáticas em Brasília, na década de 1980, foi Mário Juruna, cacique da etnia 
Xavante, da região do Mato Grosso. Esse líder indígena foi eleito deputado federal pelo Rio de Janeiro, com 31 mil votos, pelo Partido Democrático Trabalhista (PDT/Fundado em 1979 partido de centro-esquerda). Juruna cumpriu o mandato entre 1983 e 1987 e, apesar de já não atuar como deputado federal na época da aprovação da Carta Magna, ficou conhecido por frequentar o Congresso Nacional, atuando como articulador nas questões relacionadas aos direitos indígenas.

De acordo com o Portal de Notícias Gazeta de Beirute (ago. 2013), Mário Juruna já era conhecido na década de 1970 por transitar pelos gabinetes da FUNAI, em Brasília, reivindicando a demarcação de terras para os índios da etnia xavante. Entre suas atividades políticas, Juruna é lembrado por raramente abrir mão de usar um gravador portátil que sempre carregava consigo para registrar, como ele mesmo afirmava, "tudo o que o branco diz" (jornal 0 Globo, 18 jul. 2002).

Mário Juruna afirmava que, na maioria das vezes, as autoridades políticas não cumpriam com as promessas feitas. Em 1983, juntamente com Antônio Hohlfeldt e Assis Hoffmann, Mário Juruna publicou o livro intitulado: O gravador do Juruna, uma espécie de biografia política, no qual listava várias promessas feitas, muitas vezes, não cumpridas pelos dirigentes da FUNAI e por políticos aos povos indígenas (Juruna; Hohlfeldt; Hoffmann, 1982).

Enquanto isso, alguns jornais da época publicavam matérias procurando ridicularizar a atuação política de lideranças indígenas como Mário Juruna. 0 jornal Diário do Pará, na edição de 28 de novembro de 1988, de forma satírica, publicou uma anedota sobre as andanças de Juruna pelo Congresso Nacional, da seguinte maneira:

0 cacique Mário Juruna foi a Brasília há dias. No Congresso, foi à Secretaria e pediu "200 constituintes". Ninguém entendeu nada e Juruna queria porque queria. Depois de muita conversa, descobriu-se que ele queria 200 exemplares da nova Constituição (Diário do Pará, 28 nov. 1988).

Apesar do tom de sarcasmo do colunista, o tema da anedota nos chama atenção. Se o evento descrito pelo brincante ocorreu ou não, o que nos interessa neste momento é a relação entre o objeto (a Constituição) e o sujeito (o cacique Mário Juruna). De acordo com - Memorial da democracia (museu virtual produzido pelo Instituto Lula), "O maior legado de Juruna no Legislativo foi a criação da Comissão Permanente do Índio - um dos embriões da atual Comissão de Direitos Humanos e Minorias da Câmara dos Deputados" (Memorial da democracia, 2017). Tal Comissão foi a base das discussões desenvolvidas no decorrer dos processos que condicionaram as manifestações pela oficialização dos direitos indígenas no texto constitucional de 1988. 
A Comissão Permanente do Índio também representou o reconhecimento formal da necessidade de discutir e institucionalizar políticas sociais voltadas à manutenção dos direitos das minorias étnicas e sociais, especialmente aquelas que diziam respeito aos povos indígenas no Brasil. Ressalta-se, por aquela ocasião, que Mário Juruna refletia os anseios de grupos étnicos que emergiram política e socialmente no contexto da segunda metade do século XX. Nos anos 1980, democracia, cidadania e direitos humanos foram temas de primeira ordem nas agendas dos movimentos sociais. Os movimentos indígenas, para além das especificidades étnicas, não estavam alheios às mudanças políticas e nem ao contexto social brasileiro. Os projetos de falsa emancipação, empreendidos pelo Estado, nos anos 1970, também se constituíram como uma tônica para as emergências políticas de diferentes povos indígenas.

Conforme observou Eduardo Viveiros de Castro (2006), a desajeitada política empreendida no regime civil militar em direção à emancipação compulsória dos indígenas resultou na evidenciação desses sujeitos no cenário político brasileiro. Se a intenção foi livrar o Estado da responsabilidade pela defesa dos direitos indígenas, o que resultou das agitações jurídicas e sociais dos anos 1970 foi uma reação de caráter social, epistemológico e político em direção ao Estado, contradizendo suas ações no que dizia respeito ao lugar dos sujeitos indígenas na comunidade brasileira.

Ainda conforme Castro (2006), pelo menos dois fenômenos resultaram desses processos. 0 primeiro deles foi o surgimento de diversos projetos pró-indígenas em forma de associações e organizações não estatais. Como por exemplo, as Comissões Pró-Índio, a Anaís (Associação Nacional de Ação Indigenista), o Centro de Trabalho Indigenista (CTI) e o Projeto Povos Indígenas no Brasil (PIB), que esteve na origem do Instituto Socioambiental (ISA). 0 segundo foi que, em reação às propostas emancipacionistas compulsórias que tomaram fôlego nos anos 1970 e 1980, surgiram as chamadas etnias emergentes como resposta contrária às expectativas do Estado.

Observa-se que ao invés de os índios submergirem na aceleração do afastamento de suas orientações étnicas, o que se desencadeou a partir dos anos 1970 foram centenas de movimentos de emergências políticas de caráter étnico, empreendidos por comunidades indígenas, de vários lugares do Brasil, apoiadas por diferentes setores da sociedade civil. 0 caráter político e social dessas emergências é, justamente, o elemento que caracteriza os processos de etnogêneses ${ }^{5}$ empreendidos no país.

As organizações e associações pró-indígenas estabeleceram a possibilidade de ampliação das redes de conexões entre comunidades constituídas em diferentes regiões. Conforme aponta Bicalho (2010), a partir da década de 1970, vários encontros denominados de Assembleias indígenas passaram a acontecer em todo o País. A cada assembleia os povos 
indígenas fortaleciam suas articulações durante o longo processo que condicionaria, de modo significativo, os rumos que seriam tomados daqueles encontros em diante (Bicalho, 2010: 152-154). Primeiro em caráter local e regional, depois em caráter nacional e internacional, encontros foram articulados. Para tanto, um mecanismo de organização capaz de potencializar os diálogos entre as lideranças indígenas parecia elementar. Nesse ponto, o Conselho Indigenista Missionário (CIMI) surgiu como elemento facilitador ocasional, mas não indispensável.

Aqui, a nosso ver, as organizações e associações pró-indígenas não devem ser ignoradas no processo de articulação, assim como não devem ser supervalorizadas, apesar de terem sido elementos importantes naquela conjuntura, auxiliando significativamente na organização dos movimentos indígenas. Assim, sua importância não deve ser negada. Conforme aponta BicaIho (2010: 91-114), não se pode perder de vista o lugar que cada uma dessas organizações ocupava e dos jogos de interesses maiores nos quais estavam inseridas. Por fim, o lugar dessas associações e organizações pró-indígenas deve ser constantemente reavaliado à medida que os povos indígenas vão adquirindo a predominância nos processos de luta por seus direitos. Uma análise sobre as características mais gerais dos processos de conformação dos movimentos indígenas poderá nos orientar na evidenciação de suas complexidades.

\section{QUESTÕES SOBRE AS AGÊNCIAS HISTÓRICAS DOS MOVIMENTOS INDÍGENAS}

Cemas como os movimentos dos povos indígenas no Brasil e suas interpretações, o olhar
do índio e o do homem branco foram questões que, a partir dos anos 1980, resultaram em várias análises, que mesmo após esta narrativa, serão objeto de novas pesquisas e interpretações por longos anos. Não é somente porque, como diria Marc Bloch (1996), cada presente constrói a sua própria visão sobre o passado, mas, especialmente, porque ainda há muito o que se analisar nas relações estabelecidas entre tais objetos. Novos roteiros parecem surgir à medida que a sociedade e mesmo os historiadores passam a ter maior clareza da necessidade de se analisar as relações entre objetos aparentemente tão distintos como parecem ser o Estado e os povos indígenas.

Se considerarmos a relação entre ambos como parte de um processo histórico conflituoso e mesmo de um recente projeto social de caráter plurinacional, tendo em vista questões que movem relações sociais, redes de solidariedade e conexões entre direitos humanos, jurídicos e políticos, observaremos que, na relação entre Estado e políticas sociais voltadas aos 
indígenas, o contexto atual não é significativo ou de comemoração geral, apesar de alguns ganhos e vitórias circunstanciais alcançadas com o texto constitucional de 1988.

Apesar disso, entre outros fenômenos de caráter político e social ocorridos na América no decorrer do século XX, os movimentos indígenas podem ser caracterizados como estratégias de transformação social de grande complexidade para estes sujeitos e suas comunidades. Como resultado, polêmicas concernentes ao recrudescimento das políticas integracionistas para comunidades indígenas concorreram para a efervescência política que se processou desde então. ${ }^{6}$ A partir daí, estratégias exemplares de agentes indígenas resultaram em conquistas significativas relacionadas, inclusive, ao processo de cidadanização no Brasil, como veremos mais adiante.

Nos anos 1970 e 1980, as alianças desenvolvidas entre movimentos indígenas e setores da sociedade civil possibilitaram uma nova fase do protagonismo indígena por meio da criação de associações e organizações indígenas de caráter profundamente político, permitindo certa emergência social de diferentes comunidades com os movimentos sociais de caráter étnico (Fernandes; Coelho, 2017). Dessas articulações resultou uma série de conquistas que até os dias de hoje são parte de uma luta social relacionada ao longo do processo histórico do contato entre sociedades indígenas e não indígenas. A questão educacional, por exemplo, a partir de então, foi considerada um mecanismo fortalecedor de uma série de estratégias de luta que propunham conquistas e manutenção de direitos sobre territorialidades indígenas e suas correlações com outras demandas básicas ligadas à saúde e autossustentabilidade.

$\mathrm{Na}$ sociedade brasileira atual, as conquistas resultantes das históricas lutas dos movimentos sociais parecem carecer de nova investida contundente contra o Estado para que este seja pressionado a implementar políticas sociais relacionadas aos direitos conquistados pelos grupos em condições periféricas. As injustiças estão por todos os lados e constituem processos de longa duração. Guerras de conquista, expulsão de comunidades inteiras de seus territórios, genocídios e etnocídios resultantes de políticas assimilacionistas constituem a base histórica dessas relações. Poderíamos dizer que, mesmo após longos anos de articulações políticas empreendidas por plurais movimentos indígenas na América Latina, uma tempestuosa nuvem de preconceito e negligência ainda paira no ar. Desconhecimento, omissão e desrespeito às causas indígenas são características de parcelas significativas da sociedade, especialmente de alguns grupos que direcionam o País com suas bancadas no Congresso Nacional.

Em certo sentido, tais reflexões se aproximam de tendências que analisam as relações sociais a partir de uma perspectiva pessimista da história. Mas a narrativa que se propõe aqui não se encaminha nessa direção. 0 objetivo deste artigo é evidenciar que, num contexto de 
grandes crises políticas, econômicas e sociais, determinados sujeitos ou grupos (como atores, protagonistas e agentes de seu próprio caminho) são capazes de se articular contra a opressão, as limitações e o preconceito, tumultuando a ordem dominante e fazendo-a operar em benefício próprio. Nas palavras de Michel de Certeau (2014: 40), "usando inúmeras e infinitesimais metamorfoses da lei, segundo seus interesses próprios e suas próprias regras".

Para Gersem José dos Santos Luciano (2007: 127-128), índio baniwa do Alto Rio Negro e conhecida liderança indígena no Brasil, a análise da dimensão da agência indígena que reconhece a organização tradicional como a base de articulações mais amplas nos possibilita perceber a essência dos movimentos indígenas. Longe de concordar com reflexões teóricas tradicionais que consideram as gêneses dos movimentos sociais a partir de vanguardas intelectuais, Luciano Baniwa aponta para uma direção na qual é possível observar que a gênese, ou aquilo que poderíamos denominar de semente das articulações políticas indígenas, surgiu no seio das próprias comunidades tradicionais, na base social dessas articulações, e não em vanguardas intelectuais da sociedade brasileira. Pelo menos, não no sentido lato da questão.

Desse modo, a gênese dos movimentos indígenas deve ser pensada a partir do seio de suas organizações tradicionais, a partir das aldeias e das comunidades indígenas. É a partir delas que as demandas são projetadas para territórios políticos mais amplos. Tal pensamento não é apenas uma constatação de processos históricos, mas parte das próprias estratégias das representações que se intenciona projetar sobre esses movimentos. Considerar que a gênese dos movimentos indígenas está nas próprias organizações tradicionais é reconhecer que as agências indígenas em direção à manutenção de suas tradições não é de modo nenhum resultado de iniciativas exógenas de associações e organizações pró-indígenas (apesar do papel histórico que algumas delas desempenharam no financiamento de encontros indígenas de caráter regional, nacional e internacional e da intermediação nas articulações entre movimentos indígenas, comunidade civil e seus movimentos sociais). As articulações entre associações e organizações indígenas e pró-indígenas parecem ter, na verdade, possibilitado a ampliação das estratégias de apropriação de códigos da comunidade envolvente para ser usada em benefício dos movimentos indígenas e de suas comunidades.

Libertad Borges Bittencourt (2000), ao analisar os movimentos indígenas na América Latina e suas lutas para superar a exclusão política e social, observou que tais movimentos receberam apoio significativo de associações e organizações pró-indígenas. Tal cenário possibilitou a agregação de forças, tonificando as articulações políticas entre diversas comunidades indígenas dispersas geograficamente. Por outro lado, e de modo mais evidente, muitas lideranças indígenas se apropriaram de discursos relacionados às reivindicações sociais com base nas 
ideias de plurietnicidade, justiça social, proteção do meio ambiente e dos direitos humanos. Essa apropriação fez com que operassem em benefício de suas comunidades, a partir de suas reelaborações com base em representações simbólicas distintas que, ao mesmo tempo, conectavam diferentes movimentos indígenas através de demandas comuns.

Anderson Rocha de Almeida (2014: 84-109), ao analisar o papel desempenhado pelas organizações indígenas dos ticuna (grupo étnico estabelecido no Alto Solimões, no Amazonas, no território da Colômbia e do Peru) na construção do Museu Indígena Magüta, chegou a conclusões semelhantes quando observou que o alto grau de envolvimento político com organizações nacionais e internacionais possibilitou ao movimento indígena ticuna maior clareza quanto aos "meandros da cultura do homem branco". Para o autor a intensidade das relações políticas permitiu, em termos práticos, "a decodificação dos códigos da cultura do branco". Tal processo evidenciou e ampliou suas estratégias políticas frente à comunidade envolvente na medida em que os levou a vislumbrar com maior clareza as diferenças sociais e culturais existentes entre o povo ticuna e os não indígenas.

Para Daniel Munduruku (2012: 219-220), é possível pensar que houve um movimento de mão dupla nas relações estabelecidas entre movimentos indígenas e sociedade envolvente por meio das associações e organizações indígenas e pró-indígenas. De acordo com o autor, os povos indígenas aprenderam mediante à relação política com os não índios e estes aprenderam, "talvez a contragosto em alguns casos", que os indígenas poderiam se apropriar de conceitos como etnia, cultura, autodeterminação, autonomia, entre outros e usá-los em benefício próprio pelas negociações políticas com a comunidade envolvente, especialmente com as autoridades representantes do Estado. Assim, a dupla postura tomada pelos agentes indígenas no sentido de estabelecer uma crítica à sociedade brasileira, ao mesmo tempo em que tentavam disseminar representações positivas sobre seus modos de vida, tanto em nível nacional quanto internacional, permitiu-lhes apresentar-se à sociedade envolvente de modo independente da tutela da Fundação Nacional do Índio (FUNAI).

Nos anos 1970 e 1980, o termo "índio" passou a ser apropriado por diferentes grupos indígenas de modo particular, passando a operar em benefício das populações indígenas. Roberto Cardoso de Oliveira (1988) observou que:

[... A recuperação do termo "índio" se daria no bojo do Movimento Indígena, quando ele passou a ser usado para expressar uma nova categoria, forjada agora pela prática de uma política indígena e não mais pelos alienígenas, fossem eles particulares (como as missões religiosas) ou governamentais (como a Fundação Nacional do Índio - Funai) - políticas essas denominadas de indigenistas. Em oposição às políticas indigenistas começavam a surgir esboços de políticas indígenas com grandes possibilidades de, em algum momento, criarem objetivos e estratégias 
comuns suscetíveis de estabelecerem uma única e globalizadora política indígena (Oliveira, 1988, apud Munduruku, 2012).

Diante das questões apresentadas até o momento, consideramos que há uma dimensão histórica, a partir da qual, diferentes fatores levam diferentes povos indígenas a apresentarem aspectos particulares que devem ser analisados a partir de suas características históricas, sociais e culturais específicas. É inegável que os movimentos indígenas apresentam características heterogêneas, inclusive nas organizações de suas demandas perante a comunidade envolvente. No entanto, nossa proposta não se caminha na direção de evidenciar os processos históricos particulares de cada grupo étnico, mas evidenciar algumas relações que diferentes grupos sociais estabelecem entre si, a partir da "comunhão" de caráter abrangente que caracteriza a sociedade brasileira.

Nesse sentido, questões relacionadas à territorialidade, saúde, educação e autossustentabilidade parecem conectar diferentes grupos indígenas e concorrem para articulações políticas que se encaminham para procedimentos de autodeterminação em dimensões muito além daquelas de aspecto local e mesmo étnico. Apesar dos encaminhamentos dados a cada uma dessas demandas pelos diferentes grupos indígenas, acreditamos ser possível estabelecer uma conexão entre distintos movimentos indígenas na Amazônia, no Brasil e mesmo na América Latina. Por fim, outra questão que pode ser tomada como característica similar entre os diferentes movimentos indígenas é a conformação de suas associações e organizações. Em perspectiva histórica, conforme já apontado, os processos que concorrem para a institucionalização dessas relações têm sua gênese no seio das comunidades indígenas.

Isso significa dizer que procedimentos de apropriação de mecanismos da comunidade envolvente, como instituições (representadas aqui como associações e organizações políticas) e mesmo conceitos e termos ("índios", por exemplo), se constituem como parte de uma base estratégica mais ampla que legitima as demandas dos povos indígenas perante o Estado. Tais fenômenos não são recentes, mas resultam de longos processos de evidenciação da necessidade de empreender estratégias que dialoguem com as emergências políticas e sociais de agentes indígenas.

\section{QUESTÕES SOBRE MOVIMENTOS SOCIAIS E MOVIMENTOS INDÍGENAS}

o analisar as principais características dos movimentos sociais, André Gunder Frank e
Marta Fuentes (1989) defenderam, em excelente ensaio, dez teses sobre tais fenômenos. Dentre as teses apresentadas, a décima se refere à ideia de que os movimentos sociais 
contemporâneos "servem para ampliar, aprofundar e até mesmo para redefinir a democracia tradicional do Estado político e a democracia econômica para uma democracia civil numa sociedade civil" (Frank; Fuentes, 1989: 20). Os autores observaram que tais processos decorrem da participação dos movimentos sociais na ampliação e na redefinição da democracia participativa.

Em outros termos, Frank e Fuentes (1989), considerando que na tradição da prática burguesa e mesmo socialista o aspecto primordial de suas atividades diz respeito à formação do Estado e do poder, defenderam que só é possível desenvolver políticas democráticas se houver forte pressão da comunidade civil perante o Estado. Porém, mesmo quando tal pressão é exercida, forças econômicas e políticas mundiais que estão fora do controle do Estado debilitam-no a partir de fora e tendem a criar barreiras que dificultem o desenvolvimento de políticas sociais voltadas ao atendimento das demandas dos cidadãos no interior do próprio Estado (Frank; Fuentes, 1989: 46-47).

Outro problema característico da burocracia estatal, seria o trato inadequado das múltiplas preocupações sociais, culturais e individuais da sociedade civil e de seus cidadãos, já que os detentores do poder político tendem a canalizar suas forças para a consolidação do Estado e do poder. Tal problema, de acordo com Frank e Fuentes (1989: 47), torna-se mais evidente em períodos de crises econômicas e políticas, levando à constatação de que as regras estabelecidas no jogo político refletem a ineficiência do Estado no trato com as questões sociais.

Foi nesse sentido que Wanderley Guilherme dos Santos (1987), ao desenvolver uma análise relacionada às políticas sociais na sociedade brasileira, enfatizou as ideias de cidadania e justiça que decorrem das lutas por criação de políticas sociais com base na análise de determinadas conjunturas políticas. Considerando as observações do analista político Virgílio Santa Rosa, Santos (1987) observou que:

[...] A desordem é criadora porque torna manifesto os problemas, as tensões e insatisfações e outros ingredientes latentes do mundo social. Assim, uma situação de crise pode constituir importante fonte de mudança nas decisões da elite, não obstante baixa taxa de renovação, na medida em que estimula o surgimento de comportamentos inovadores, por um lado, e, por outro, traz à luz aspectos insuspeitos do mundo exterior à própria elite (Santos, 1987: 55).

Considerando as observações do autor, no que concerne à força das organizações pela pressão que exercem frente ao Estado e defendendo a ideia de que as demandas sociais apenas se encaminham para a construção de políticas sociais quando existem organizações que pressionam o Estado pela criação de tais políticas, podemos considerar que se houve reconhecimento constitucional dos direitos indígenas, foi porque havia associações e organizações indígenas for- 
tes que pressionaram o Estado, reivindicando o reconhecimento de suas diferenças, a cidadania plena e o desenvolvimento de políticas sociais voltadas para suas comunidades. 0 modo pelo qual grupos indígenas lutaram pela cidadania, como forma de reivindicar a criação de políticas sociais que considerassem suas especificidades, concorreu para uma mudança importante no modo como a sociedade brasileira entendia as relações entre cidadania e políticas sociais.

Se até os anos 1970 as políticas sociais foram consideradas pelo próprio Estado e mesmo pensados pela sociedade como uma concessão para os cidadãos, o que ocorre a partir das emergências políticas dos movimentos indígenas é uma modificação desse modo de lidar com as demandas essenciais ao bem-estar social. A questão é que ao reivindicar o reconhecimento da cidadania plena, os povos indígenas não queriam apenas ser considerados cidadãos brasileiros, mas fundamentar suas reivindicações pela criação de políticas sociais que atendessem às suas demandas (territorialidade, saúde e educação). Desse modo, os movimentos indígenas foram elementos importantes para uma renovação do modo pelo qual a relação entre políticas sociais e Estado foram, até então, pensadas. As agências indígenas, iniciadas nos anos 1970, levaram a comunidade brasileira ao entendimento de que políticas sociais são um direito dos cidadãos e uma responsabilidade do Estado, e não uma concessão deste último!

Tal processo contribuiu para uma transformação na mentalidade política de milhares de brasileiros que, articulados em diferentes tipos e categorias de movimentos sociais, passaram a reivindicar políticas sociais como parte do exercício de cidadania. Nesse sentido, a ideia de cidadanização precisa ser pensada como um processo a partir do qual a relação entre Estado, políticas sociais e cidadania passou a operar sob novas representações, indicando que tanto - Estado quanto as políticas sociais implementadas pelos governos deveriam ser refletidas como elementos a serviço da democracia, instaurando, no Brasil, a compreensão de que o cidadão é o agente central de todo o processo estatal e da manutenção dos direitos e das responsabilidades sociais.

No caso dos povos indígenas, a luta pela cidadanização foi importante para evidenciar um agente social que exercia sua cidadania (por meio das agências políticas) sem o direito ao usufruto das políticas sociais. 0 exercício de cidadania parece ter se estabelecido como uma constante nos movimentos indígenas antes mesmo do reconhecimento constitucional de suas diferenças e especificidades.

Apesar de nos últimos anos termos visto a instalação de uma crise política que evidencia os limites e as possibilidades da democracia representativa, os processos que tomaram forma nos anos 1980 concorreram para a criação das bases sociais que sustentam a concepção de democracia no Brasil atual. Aqui, mais uma vez, as agências indígenas auxiliaram na formação do pensamento social e político brasileiro. 


\section{CONSIDERAÇÕES PONTUAIS}

$\mathrm{D}$ iante das considerações feitas até o presente, é importante pensar os movimentos indígenas numa perspectiva anticolonialista. Ao reivindicar direitos sociais e o reconhecimento da diversidade, em detrimento de projetos integracionistas, tais movimentos evidenciam suas naturezas profundamente decoloniais. Nelson Maldonado-Torres (2016: 88) observou que uma atitude decolonial "encontra suas raízes nos projetos insurgentes que resistem, questionam e buscam mudar padrões coloniais do ser, do saber e do poder". No Brasil, os movimentos indígenas atuam nessas três dimensões.

\section{NOTAS}

1 Para uma reflexão sobre o fenômeno do nacionalismo e a emergência dos Estados nacionais, assim como sobre as ideias relacionadas com a consciência nacional e a nacionalidade, ver Anderson (1989; 1993) e Curto, Jerónimo e Domingos (2002: 33-58).

2 Como exemplo de trabalho recente sobre o tema dos chamados Estados plurinacionais, tomamos a tese de Rosane Freire Lacerda (2014).

3 Sobre a questão agrária no Brasil, é possível acessar o Banco de Teses e Dissertações da Biblioteca Digital da Questão Agrária Brasileira. Nesse portal, há o acervo com pesquisas desenvolvidas desde 1985, além de centenas de fontes sobre 0 assunto. 0 portal pode ser acessado no endereço: <http://www.reformaagrariaemdados.org.br/biblioteca>. Acesso em: 6 fev. 2017.

4 Para defender tal hipótese, permitimo-nos considerar a segunda tese apresentada por André Gunder Frank e Marta Fuentes (1989: 28-48). A partir dela, os autores observam que "os movimentos sociais demonstram muita variedade e mutabilidade, mas têm em comum a mobilização individual baseada num sentimento de moralidade e (in)justiça e num poder social baseado na mobilização social contra as privações (exclusões) e pela sobrevivência e identidade".

5 Bartolomé (2006: 59) observa que o fenômeno das etnogêneses destaca "o dinamismo inerente às estruturas sociais, uma vez que tais estruturas não atuam sobre agentes passivos, mas sobre sujeitos ativos, capazes de modificá-las de acordo com seus interesses contextuais". Dessa forma, tais ideias têm relação com os processos de emergência política e social dos povos indígenas nos contextos nacional e internacional. Citando Jonathan Hill (1996), Bartolomé (2006: 39) destacou que "o conceito de etnogênese foi utilizado na análise dos recorrentes processos de emergência social e política dos grupos tradicionalmente submetidos a relações de dominação".

6 Polêmicas relacionadas com questões como tutela e emancipação indígena, desenvolvidas nos anos 1970, constituíram-se em base de uma discussão que possibilitou emergências políticas e sociais de determinados movimentos indígenas e a ampliação da articulação de tais movimentos, como algumas organizações de caráter civil que desempenharam papel importante, mas não central, nos rumos que possibilitaram emergências sociais de alguns grupos ainda no contexto do regime civil militar no Brasil (Fernandes; Coelho, 2017). 


\section{FONTES UTILIZADAS:}

ATRIBUIÇÕES constitucionais e regimentais da Comissão de Direitos Humanos e Minorias (CDHM). Disponível em: <http://www2.camara.leg.br/atividade-legislativa/comissoes/comissoes-permanentes/cdhm/conheca-a-comissao/oquee.html>. Acesso em: 6 fev. 2017.

BATALHA semanal. Jornal Diário do Pará, Belém, segunda-feira, ano VI, n. 1955, p. D-7, 28 nov. 1988. Hemeroteca Digital Brasileira, Fundação Biblioteca Nacional. Disponível em: <http://memoria.bn.br/DocReader/ docreader.aspx? bib=644781\&pasta=ano $\% 20198 \&$ pesq $=$ Segunda-Feira, $\% 2028 \% 20$ de $\% 20$ Novembro $\% 20$ de\%201988>. Acesso em: 5 dez. 2017.

CACIQUE Mário Juruna, deputado federal. Disponível em: <http://www.gazetadebeirute.com/2013/08/cacique-mario-juruna-deputadofederal.html\# ixzz4XyANGL3b>. Acesso em: 6 fev. 2017.

DISCURSO do deputado federal de São Paulo Luiz Inácio Lula da Silva, proferido na sessão de 22 de setembro de 1988, publicado no DANC de 23 de setembro de 1988, p. 14.313-14.314. Disponível em: <http://www2.camara.leg.br/atividade-legislativa/ plenario/discursos/escrevendohistoria/25-anos-da-constituicao-de-1988/constituinte19 871988/pdf/Luiz\%20Inacio\%20\%20DISCURSO\%20\%20REVISADO.pdf>. Acesso em: 31 jan. 2017.

2 DE FEVEREIRO de 1983: Juruna, $1^{\circ}$ deputado índio toma posse. Eleito pelo PDT do Rio, o líder Xavante criou a Comissão do Índio na Câmara. Disponível em: <http://memorialdademocracia.com.br/card/juruna-1-deputado-indio-toma-posse>. Acesso em: 31 jan. 2017.

DOS 64 ausentes, 15 foram para a Europa. Jornal do Brasil, Rio de Janeiro, 2. ed., sexta-feira, ano XCVIII, n. 168, p. 2 , 23 set. 1988. Hemeroteca Digital Brasileira, Fundação Biblioteca Nacional. Disponível em: <http:// memoria.bn.br/DocReader/docreader.aspx?bib=030015_10\&pasta=ano\%20198\&pesq=Dos\%2064\%20 ausentes>. Acesso em: 5 dez. 2017.

JURUNA, um gravador na mão em defesa da causa indígena. Revista Época, n. 217, 18 jul. 2002. Disponível em: <http://revistaepoca.globo.com/Revista/Epoca/0,EDG49129-6014,00JURUNA+UM+GRAVADOR+NA+MAO+EM+DEFESA+DA+CAUSA+INDIGENA.html>. Acesso em: 6 fev. 2017.

LÍDERES vão à tribuna para comemorar avanço da nova Constituição. Jornal do Brasil, Rio de Janeiro, 2. ed., sexta-feira, ano XCVIII, n. 168, p. 4, 23 set. 1988. Hemeroteca Digital Brasileira, Fundação Biblioteca Nacional. Disponível em: <http://memoria.bn.br/DocReader/docreader.aspx?bib=030015_10\&pasta=ano\%20 198\&pesq=comemorar\%20avan\%C3\%A70\%20da\%20nova\%20Constituil\%C3\%A7\%C3\%A30>. Acesso em: 5 dez. 2017.

NOVA Constituinte tem texto definitivo. Jornal do Brasil, Rio de Janeiro, 2. ed., sexta-feira, ano XCVIII, n. 168, p. 2, 23 set. 1988. Hemeroteca Digital Brasileira, Fundação Biblioteca Nacional. Disponível em: <http:// memoria.bn.br/DocReader/docreader.aspx?bib=030015_10\&pasta=ano\%20198\&pesq=Constituinte $\% 20$ tem\%20texto\%20definitivo>. Acesso em: 5 dez. 2017.

PDS e PFL juram respeito à Carta. Jornal do Brasil, Rio de Janeiro, 2. ed., sexta-feira, ano XCVIII, n. 168, p. 1, 23 set. 1988. Hemeroteca Digital Brasileira, Fundação Biblioteca Nacional. Disponível em: <http://memoria.bn.br/DocReader/docreader.aspx?bib=030015_10\&pasta=ano\%20198\&pesq=PDS $\% 20$ e $\% 20 \mathrm{PFL} \% 20$ juram\%20respeito\%20\%C3\%A0\%20Carta>. Acesso em: 5 dez. 2017. 


\section{REFERÊNCIAS BIBLIOGRÁFICAS:}

ALMEIDA, Anderson Rocha de. Movimento indígena no Brasil: o papel das organizações ticuna nesse percurso (Parte III - Museu Magüta: instrumento de afirmação de identidade étnica). Revista Zona de Impacto, ano 6, p. 84-109, jan./jun. 2014. Disponível em: <http://www.revistazonadeimpacto.unir.br/Anderson\%2016\%201. pdf>. Acesso em: 19 nov. 2017.

ANDERSON, Benedict. Comunidades imaginadas: reflexiones sobre el origen y la difusión del nacionalismo. Tradução de Eduardo L. Suárez. México: Fondo de Cultura Económica, 1993. Disponível em: <http://www. perio.unlp.edu.ar/catedras/ system/files/anderson_benedict_comunidades_imaginadas.pdf $>$. Acesso em: 6 fev. 2017.

Nação e consciência nacional. São Paulo: Ática, 1989. Disponível em: <https://pt.scribd.com/ doc/75948005/Nacao-e-Consciencia-Nacional-Atica-ANDERSON-B>. Acesso em: 5 dez. 2017.

BARTOLOMÉ, Miguel Alberto. As etnogêneses: velhos atores e novos papéis no cenário cultural e político. Tradução de Sergio Paulo Benevides. Mana: Revista do Programa de Pós-graduação em Antropologia Social, Rio de Janeiro: Universidade Federal do Rio de Janeiro, Museu Nacional, v. 12, 2006. Disponível em: <http:// www.scielo.br/scielo.php?script=sci_arttext\&pid=S0104-93132006000100002 >. Acesso em: 5 dez. 2017.

BICALHO, Poliene Soares dos Santos. As assembleias indígenas: o advento do movimento indígena no Brasil. Opsis, Catalão, v. 10, n. 1, p. 91-114, 2010. Disponível em: <https://revistas.ufg.br/Opsis/article/ view/9553/8474\#.Wia28VWnF0w>. Acesso em: 5 dez. 2017.

Protagonismo indígena no Brasil: movimento, cidadania e direitos (1970-2009). Tese (Doutorado) Instituto de Ciências Humanas, Departamento de História, Universidade de Brasília, Brasília, 2010. Disponível em: <http://repositorio.unb.br/bitstream/10482/6959/1/2010_PolieneSoaresdosSantosBicalho.pdf>. Acesso em: 5 dez. 2017.

BITTENCOURT, Libertad Borges. 0 movimento indígena organizado na América Latina: a luta para superar a exclusão. Anais Eletrônicos do IV Encontro da ANPHLAC. Salvador, 2000. Disponível em: <http://anphlac. fflch.usp.br/sites/anphlac.fflch.usp.br/files/libertad_bittencourt.pdf>. Acesso em: 18 nov. 2017.

BLOCH, Marc. Apología para la historia o el oficio de historiador. Tradução de María Jiménez e Danielle Zaslavsky. México: Fondo de Cultura Económica, 1996. Disponível em: <https://s3.amazonaws.com/academia.edu.documents/35275045/BD001_Bloch01.pdf?AWSAccessKeyld=AKIAIWOWYYGZ2Y53UL3A\&Expi-

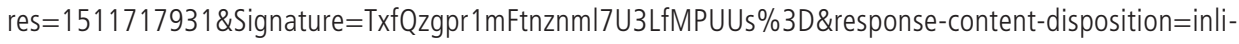
ne\%3B\%20filename\%3DBD001_Bloch01.pdf>. Acesso em: 26 nov. 2017.

CASTRO, Eduardo Viveiros de. No Brasil, todo mundo é índio, exceto quem não é. Povos indígenas no Brasil (2001/2005). 2006. p. 41-49. Disponível em: <https://pib.socioambiental.org/files/file/PIB_institucional/ No_Brasil_todo_mundo_\%C3\%A9_\%C3\%ADndio.pdf>.Acesso em: 18 nov. 2017.

CERTEAU, Michel de. A invenção do cotidiano: 1. Artes de fazer. Tradução de Ephraim Ferreira Alves. 22. ed. Petrópolis: Vozes, 2014.

CURTO, Diogo Ramada; JERÓNIMO, Miguel Bandeira; DOMINGOS, Nuno. Nações e nacionalismos (a teoria, a história, a moral). Tradução de Otacílio Nunes. Tempo Social: Revista de Sociologia da USP, v. 24, n. 2, p. 3358, 2002. Disponível em: <http://www.scielo.br/pdf/ts/v24n2/v24n2a03>. Acesso em: 6 fev. 2017. 
FERNANDES, Fernando Roque; COELHO, Mauro Cezar. Integração e emancipação: apontamentos para uma reflexão sobre o protagonismo indígena nos anos 70 e 80. In: II SEMINÁRIO INTERNACIONAL DA AMÉRICA LATINA: POLÍTICA E CONFLITOS CONTEMPORÂNEOS. Anais... Belém: Naea, 2017. v. 9, p. 4379-4392. Disponível em: <http://sialat2017.com/wp-content/uploads/2017/11/GT-09-COMPLETO-internet.pdf>. Acesso em: 5 dez. 2017.

FRANK, André Gunder; FUENTES, Marta. Dez teses acerca dos movimentos sociais. Tradução de Suely Bastos. Lua Nova, São Paulo, n. 17, p. 28-48, jun. 1989. Disponível em: <http://www.scielo.br/pdf/ln/n17/a03n17. pdf>. Acesso em: 20 jan. 2017.

HILL, Jonathan (Ed.). History, power and identity. lowa, USA: University of lowa Press, 1996.

JURUNA, Mário; HOHLFELDT, Antônio; HOFFMANN, Assis. O gravador do Juruna. Mercado Aberto, 1982.

LACERDA, Rosane Freire. "Volveré, y Seré Millones": contribuições descoloniais dos movimentos indígenas latino-americanos para a superação do mito do Estado-Nação. Tese (Doutorado em Direito) - Programa de Pós-graduação em Direito, Faculdade de Direito, Universidade de Brasília, Brasília, 2014. Disponível em: <http://bdtd.ibict.br/vufind/Record/UNB_a115f51f61ea34b531b20a586bb43405>. Acesso em: 5 dez. 2017.

LUCIANO, Gersem José dos Santos. Movimentos e políticas indígenas no Brasil contemporâneo. Tellus: Escritos Indígenas, Campo Grande, ano 7, n. 12, p. 127-146, abr. 2007. Disponível em: <http://tellus.ucdb.br/ projetos/tellus/index.php/tellus/article/view/136/140>. Acesso em: 15 jul. 2017.

MALDONADO-TORRES, Nelson. Transdisciplinaridade e decolonialidade. Tradução de Joaze Bernandino-Costa. Revista Sociedade e Estado, v. 31, n. 1, p. 75-97, 2017. Disponível em: <http://www.scielo.br/scielo.php?pi$d=S 0102-69922016000100075 \&$ script=sci_arttext\&tlng=pt>. Acesso em: 5 dez. 2017.

MUNDURUKU, Daniel. O caráter educativo do movimento indígena brasileiro (1970-1990). São Paulo: Paulinas, 2012.

OLIVEIRA, Roberto Cardoso de. A crise do indigenismo. Campinas: Unicamp, 1988.

RIBEIRO, Tânia Guimarães. O conceito de desenvolvimento participativo nas ações do Estado: uma proposta para a Amazônia. Tese (Doutorado) - Programa de Pós-graduação em Sociologia e Antropologia, Universidade Federal do Rio de Janeiro, Rio de Janeiro, 2010. Disponível em: <http://livros01.livrosgratis.com.br/cp147541. pdf>. Acesso em: 5 dez. 2017.

SANTOS, Wanderley Guilherme dos. Cidadania e justiça: a política social na ordem brasileira. 2. ed. Rio de Janeiro: Campos, 1987 [1979]. 